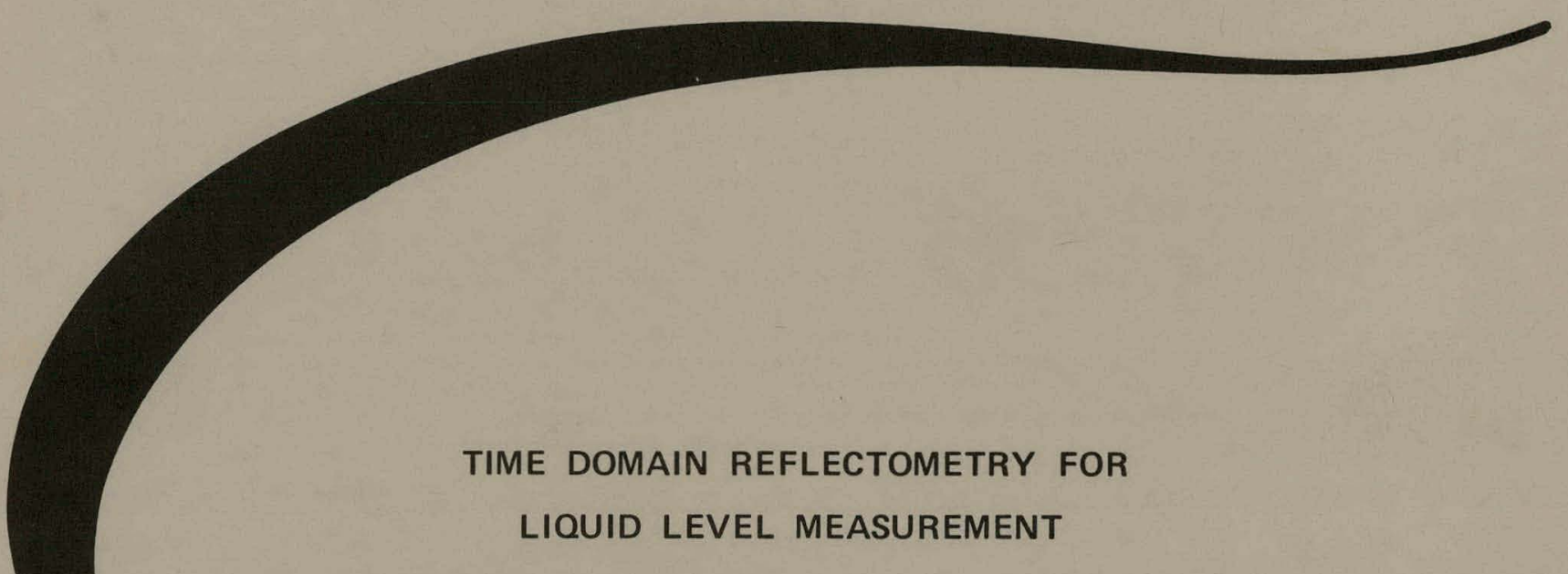

George D. LehmkuhI

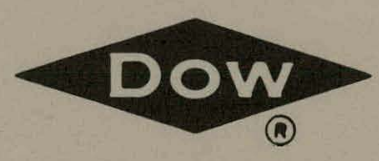

DOW CHEMICAL U.S.A. ROCKY FLATS DIVISION P. O. BOX 888 GOLDEN, COLORADO 80401

U. S. ATOMIC ENERGY COMMISSION CONTRACT AT(29-1)-1106 


\section{DISCLAIMER}

This report was prepared as an account of work sponsored by an agency of the United States Government. Neither the United States Government nor any agency Thereof, nor any of their employees, makes any warranty, express or implied, or assumes any legal liability or responsibility for the accuracy, completeness, or usefulness of any information, apparatus, product, or process disclosed, or represents that its use would not infringe privately owned rights. Reference herein to any specific commercial product, process, or service by trade name, trademark, manufacturer, or otherwise does not necessarily constitute or imply its endorsement, recommendation, or favoring by the United States Government or any agency thereof. The views and opinions of authors expressed herein do not necessarily state or reflect those of the United States Government or any agency thereof. 


\section{DISCLAIMER}

Portions of this document may be illegible in electronic image products. Images are produced from the best available original document. 


\section{LEGAL NOTICE}

This report was prepared as an account of work sponsored by the United States (iovernment. Neither the United States nor the United States Atomic Energy Commission, nor any of their employees, nor any of their contractors, subcontractors, or their employees, makes any warranty, expressed or implied, or assumes any legal liability or responsibility for the accuracy, completeness or usefulness of any information, apparatus, product or process disclosed, or represents that its use would not infringe privately owned rights.

Printed in the United States of America

Available from the

National Technical Information Service

U. S. Department of Commerce

Springfield, Virginia 22151

Price: Printed Copy $\$ 3.00$; Microfiche $\$ 0.95$ 


\title{
TIME DOMAIN REFLECTOMETRY FOR LIQUID LEVEL MEASUREMENT
}

\author{
George D. Lehmkuhl
}

\section{NOTICE}

This report was prepared as an account of work sponsored by the United States Government. Neither the United States nor the United States Atomic Energy Commission, nor any of their employees, nor any of their contractors, subcontractors, of theip employees, makes any warranty, express or implied, or assumes any legal liability or responsibility for the accuracy, completeness or usefulness of any information, apparatis, product or process disclosed, or represents that its use would not infringe privately owned rights.

DOW CHEMICAL U.S.A.

ROCKY FLATS DIVISION

P. O. BOX 888

GOLDEN, COLORADO 80401

Prepared under Contract AT(29-1)-1106

for the

Albuquerque Operations Office

U. S. Atomic tnergy Commissiun 
RFP-1902 
CONTENTS

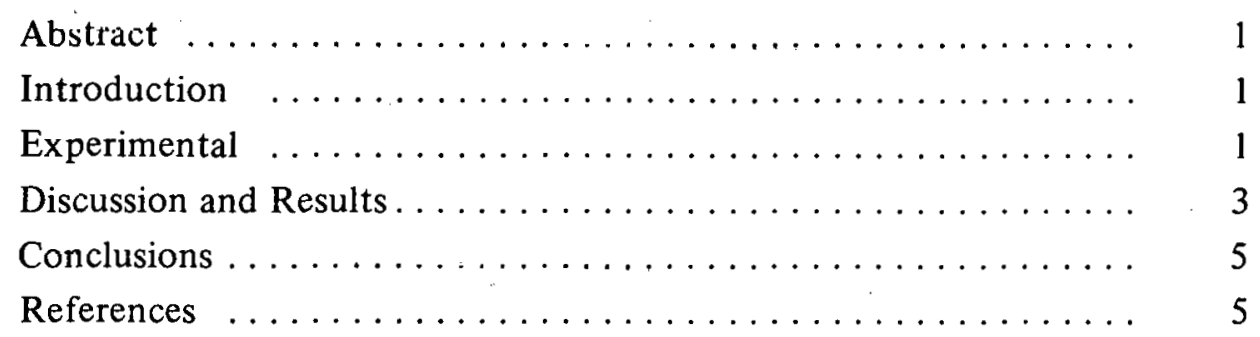


RFP-1902

\section{ACKNOWLEDGMENTS}

The author cxpresses lis appreclation to $\mathrm{L}$. W. Woher for aid in expediting equipment acquisition and construction, and in inquiring about the use of lime domain reflectometry in the field of atomic energy in the United States and abroad; and to J. K. Patterson for performing a majority of the experimental work. The use of the time domain reflectometry electronic equipment furnished by the Hewlett-Packard Company is also appreciated. 


\title{
TIME DOMAIN REFLECTOMETRY FOR LIQUID LEVEL MEASUREMENT
}

\author{
George D. Lehmkuhl
}

\begin{abstract}
The time domain reflectometry technique was used to measure liquid levels in a tank. Remote readings of liquid level were easily obtained. The state-of-the-art allows direct readout of volume, level, or pulse travel time through use of proper calibration techniques and a computer-calculator. Calibration and readout using the same fluid allowed level measurement of $\pm 0.3 \mathrm{~cm}$. When solutions of different ionic strengths were used for calibration and readout, the errors in liquid level measurement varied from $\pm 1 \mathrm{~cm}$ to $\pm 4 \mathrm{~cm}$. The magnitude of the error depended on the difference in ionic strength and on the trigger voltages used in the electronic instrumentation.
\end{abstract}

\section{INTRODUCTION}

More accurate methods of liquid level measurements are required as the need for stricter nuclear materials accountability increases. Sight gages are very accurate level indicators for open area tanks. Measurement is more difficult in closed areas, such as canyons, where direct visual observations are not possible. One method for remote liquid level measurement, time dumain reflectometry (TDR), uses an electronic signal sent along a transmission line and reflected off the liquid surface.

A ventilated transmission line dipping into a liquid will show an impedance mismatch at the point of entry. A coaxial probe and TDR instrumentation give a liquid level gage that can work in an environment where radioactive materials are present. Either a step function or pulse may be sent down the transmission line (traveling at the speed of electromagnetic radiation in the transmission line). When a change in the impedance of the line is encountered by the advancing wave, a reflection occurs. This reflection can be detected as it returns to the source end of the transmission line. ${ }^{1,2,3}$ The time interval between the initial wave and the reflection can be used as a measure of the distance to the impedance change. In this case, part of the transmission line is an air dielectric probe. The probe is placed into a tank of liquid so that the liquid can flow freely into the probe and seek the same level as the liquid in the tank. The change in impedance of the line at the liquid interface causes a reflection which is easily seen. This reflection is used to measure the depth of liquid in the tank.

\section{EXPERIMENTAL}

A tank was calibrated according to Rocky Flats standard operating procedures ${ }^{4,5}$ using standard volumes and a linear measuring device (sight gage). Simultaneous readings were taken on the sight gage and on the TDR equipment. Readings were taken both filling the tank and draining the tank. Experiments were run using several different fluids. These included water and several concentrations of nitric acid and sodium chloride solutions. Experiments were performed with and without Raschig rings in the tank. Experiments were also performed in which the triggering levels in the electronic time interval measuring equipment were varied.

The general equipment outlay is shown in Figures 1 and 2. The pulse generation equipment was set to give a nominal 10-nanosecond (nsec) pulse width and 5 volt pulse height The pulse-rise time was measured as approximately $0.5 \mathrm{nsec}$. The pulse repetition rate was nominally 1 kilohertz. The computing counter was set to average many measurements and display this average to \pm 1 picosecond. The readings were taken with the counter averaging 10,000 measurements per display then 5 to 10 displays were manually averaged for each datum point. The starting point for the time interval measurement was a preselected voltage on the initial pulse. This voltage was set on the time-interval unit and could be varied between 0 and 3 volts. It was usually set near the 2.5 -volt level (this voltage was fixed during each experiment to obtain consistent readings). Similarly, the stop-point voltage on the return pulse was set on the time interval unit. 


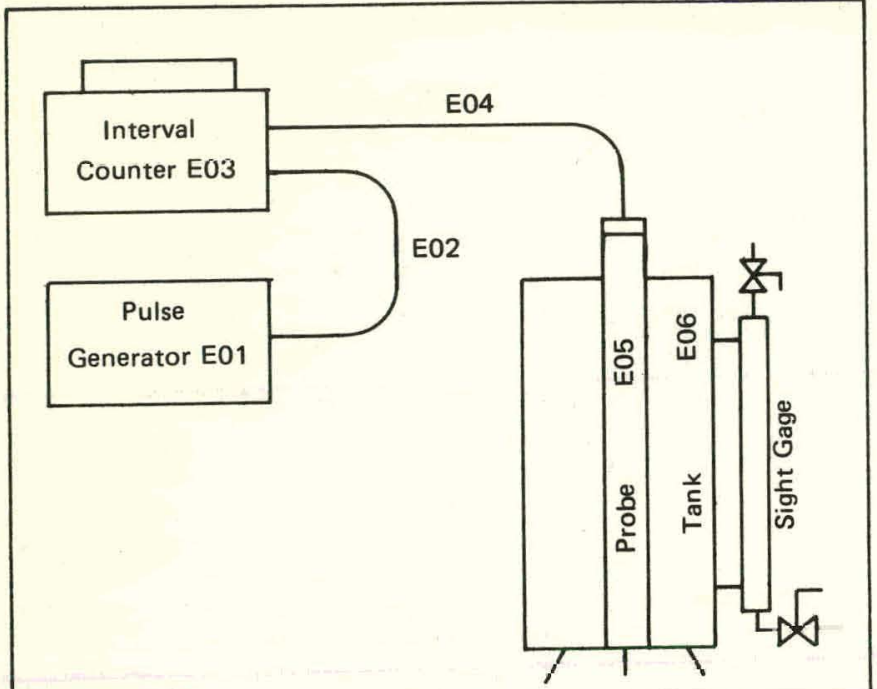

EO1 - Hewlett-Packard Model 1905A Pulse Rate Generator and Hewlett-Packard Model 1920 A Pulse Shaping Unit.

EO2 - 2 ft RG $58 \mathrm{c} / \mathrm{u}$ Coaxial Cable, $50 \mathrm{ohm}$.

EO3 - Hewlett-Packard Model 5379A Time Interval Unit and Hewlett-Packard Model 5360A Computing Counter with Model 5375 A Keyboard.

EO4 - $9 \mathrm{ft}$ RG $58 \mathrm{c} / \mathrm{u}$ Coaxial Cable, $50 \mathrm{ohm}$.

EO5 - Air Dielectric Ventilated Coaxial Probe.

EO6 - Stainless Steel Tank (47-in. high, 10-1/4 in. diameter) with sight gage.

FIGURE 1. Equipment Diagram.

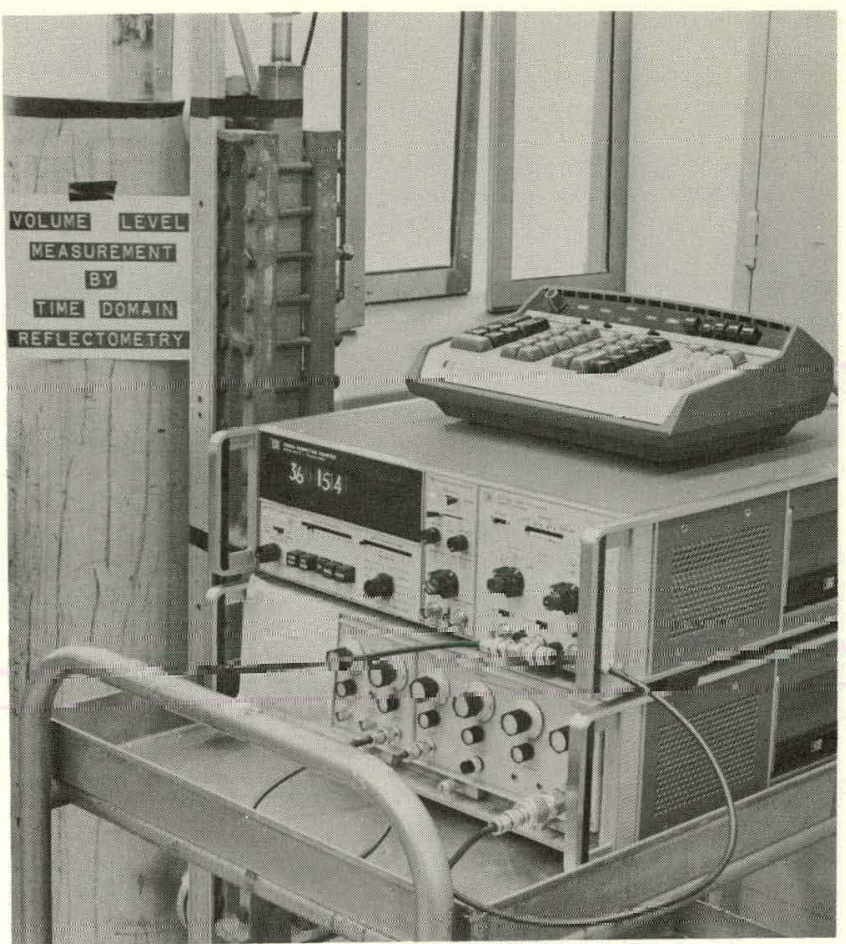

FIGURE 2. Photograph of Experimental Layout.

The probe, shown in Figure 3, was made of two stainless steel pipes 3/4-in. and 2-in. outside diameters. The pipes were coaxial, held in place

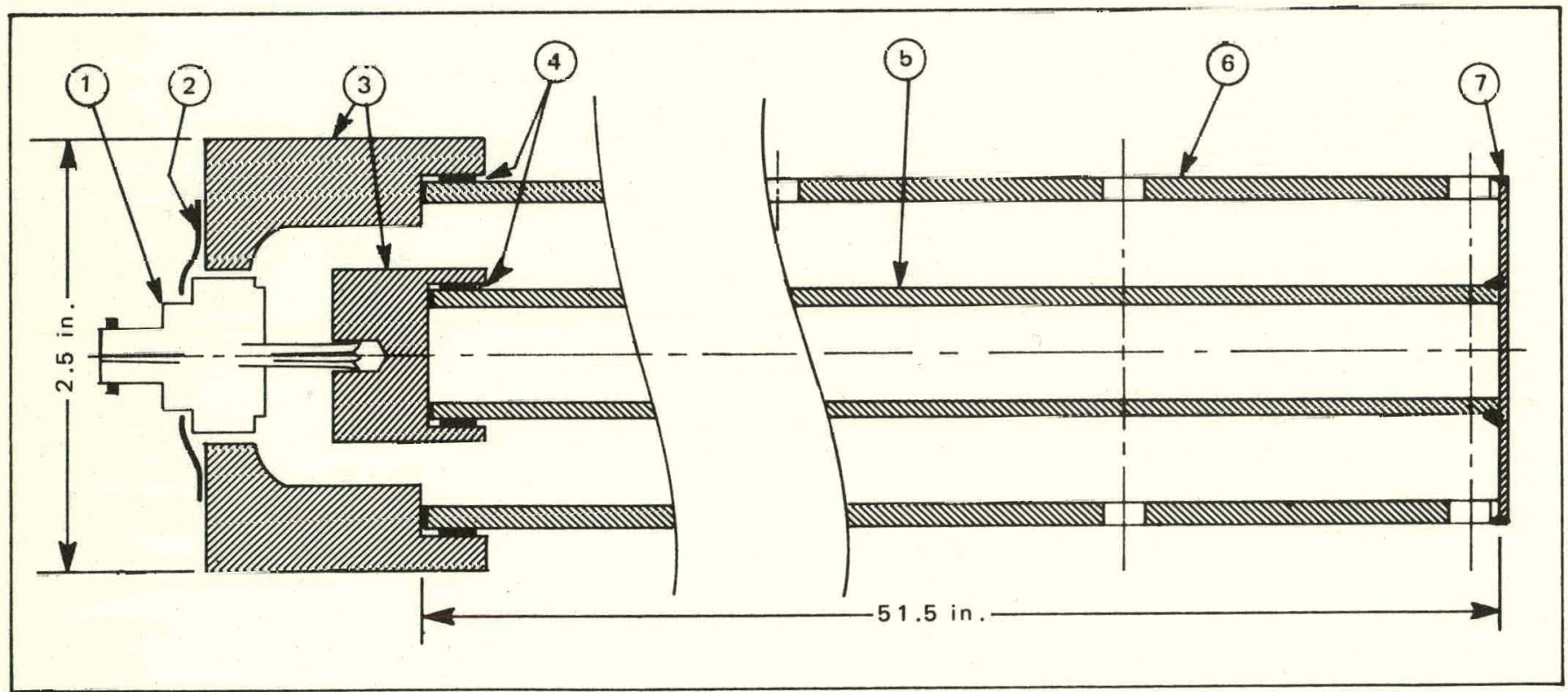

1. A modified GR-874-QBJA connector

2. Copper foil soldered to the GR-874-QBJA connector and the outer copper adapter block.

3. Adapter pieces machined from copper stock.

4. The copper adapter pieces are press fit to the stainless steel tubes over thin rings of copper soldered to the stainless steel tubes.
5. The inner stainless steel tube is $3 / 4$-in. o.d. and is welded to the bottom plate.

6. The outer stainless steel tube is 2 -in. o.d. and has 0.120 -in. thick walls. It is welded to the bottom plate and has two rows of $1 / 4$-in. - diameter holes, diametrically opposed, 2-in. apart along the side of the tube.

7. The bottom plate is $1 / 8$-in. stainless steel.

FIGURE 3. Level Sensing Probe. 
by being welded to a bottom plate of 1/16-in. stainless steel and by an annular Teflon $®$ spacer near the top of the probe. A connector at the top of the probe was made of copper and a modified General Radio Company GR-874-QBJA connector. The probe was ventilated to allow liquid to flow freely into the annular space between the two pipes. The ventilation was accomplished by drilling two rows of 1/4-in.-diameter holes, diametrically opposed, along the outer pipe. These holes were spaced 2-in. apart. The probe pipe diameters. were chosen in an attempt to obtain a probe impedance of approximately $50.0 \mathrm{hms}$ to match the RG-58 c/u, 50-ohm cable portion of the transmission line. The design seemed satisfactory, as no gross impedance mismatch was detected.

The tank was 10-1/4 in. in diameter and 47-in. high. It was constructed of stainless steel pipe with a bottom plate of 1/8-in. stainless steel. The tank was fitted with a sight gage and rule for measuring the liquid level in the tank. Drains were provided at the bottom of the tank and bottom of the sight gage. The TDR probe was placed down the center of the tank and held in position by a centering arrangement at the top of the tank.

\section{DISCUSSION AND RESULTS}

The purpose of these experiments was to determine how accurately the liquid level in a tank could be remotely determined using the time domain reflectometry technique. Ideally, any level detection instrument should give exactly reproducible readings. There should be no change from day to day (zero drift). The readings should also be independent of the solutes or solute concentrations in the liquid.

A sight gage was used as the standard in the experiments and all TDR readings were compared to the sight-gage readings. The sight-gage readings are accurate within $\pm 0.5 \mathrm{~mm}$. Comparison readings were taken both as the tank was filled and as the tank was drained.

A plot of centimeter sight-gage readings versus nanosecond TDR readings is shown in Figure 4. The error (standard deviation) in liquid level for a given TDR reading is $0.26 \mathrm{~cm}$. Therefore, $95 \%$ of all readings should fall within $\pm 0.5 \mathrm{~cm}$ of the curve. Data for this plot were taken with water as the liquid. Data were taken over several days, both filling and draining the tank, with and without Raschig rings in the tank. The myriad of

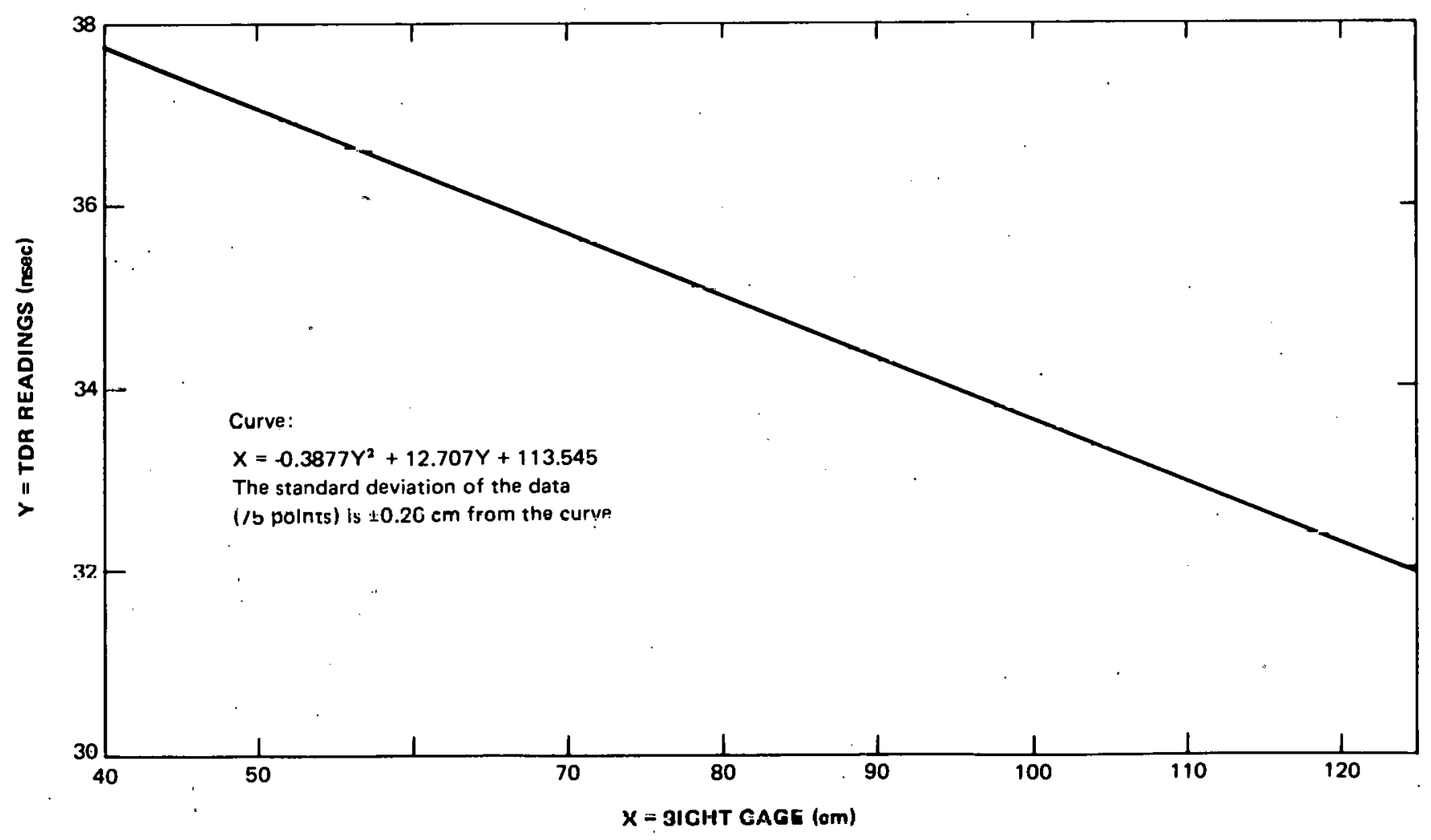

FIGURE 4. Sight-Gage Readings for Water. 
points are not shown in the figure; only the second order polynomial curve fit through the points is shown. The bottom of the tank is not at zero for sight-gage readings or for TDR readings.

The tank bottom is at $10.50 \mathrm{~cm}$ and $39.250 \mathrm{nsec}$, respectively. The centimeter reading values increase as the tank is filled, whereas the nanosecond reading values decrease as the tank is filled. This decrease in nanosecond values with increase in liquid depth occurs because the TDR measurement is from the top of the probe down to the interface. Readings taken for nitric acid and for sodium chloride solutions gave similarly good results; the level readings are reproducible.

Problems arise, however, when liquid-level readings for various electrolyte concentrations are. compared. That is, for a fixed liquid level in the tank and for fixed electronic equipment settings, the TDR instrumentation will give different readings for different electrolyte concentrations in the liquid. Figure 5 shows this variation for sodium chloride solutions. The electronic settings for the data in Figure 5 are different from the settings for Figure 4 and, therefore, the water data do not directly compare. These variations would not be a problem if the calibration fluid and the fluid in the tank were exactly the same, or differed only slightly: The problems occur in a case such as calibrating with water and then trying to measure a liquid level of $7 N$ nitric acid solution in the tank; the measurement could be a few centimeters in error.

The amount of variation of TDR reading with electrolyte concentration depended on the trigger voltage settings on the time interval unit. The ideal voltage waveform for the initial pulse and reflected pulse in the probe transmission line are shown in Figure 6A. The ideal pulses have zero rise time (vertical leading edges as indicated by Number 1 on the figure). The time interval measurement, $\Delta \mathrm{T}$, therefore, does not depend on the trigger level voltages, TL1 and TL2. Howcver, the artulal pulses have apprcciable rise times and the time interval, $\Delta T$, depends on the trigger voltages as seen in Figure $6 \mathrm{~B}$ (see Numbers 2 and 4). Varying the initial trigger voltage TL1, between 0.5 and 3 volts would change the measured time interval, $\Delta \mathrm{T}$, by $0.6 \mathrm{nsec}$ and varying the reflected pulse trigger voltage between -0.5 and 3 volts would change the time interval by $2.5 \mathrm{nsec}$. Since a $1-\mathrm{cm}$ change in liquid levelcorresponds to only $0.07 \mathrm{nsec}$, a change in trigger voltage can make a difference of many centimeters.

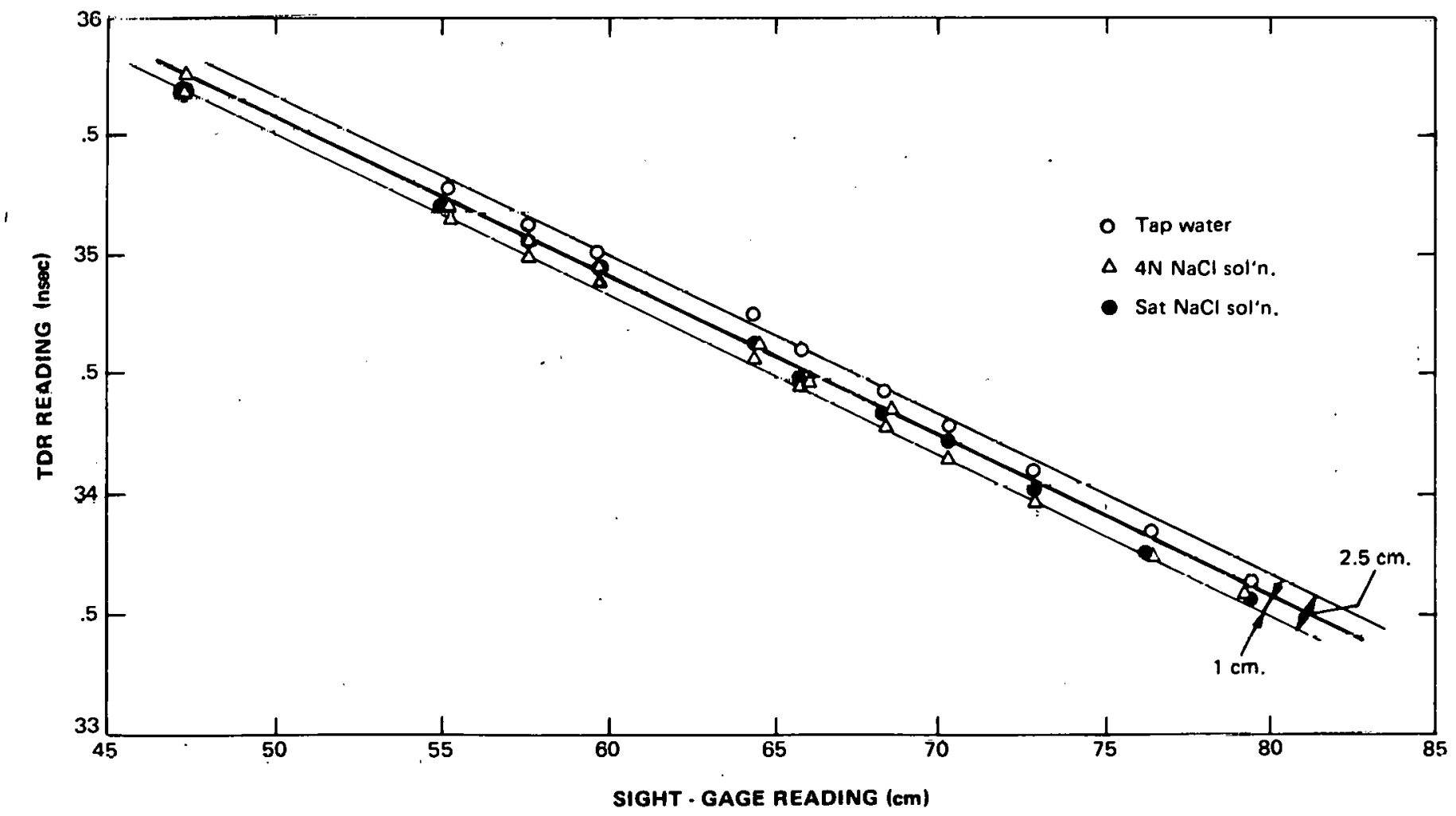

FIGURE 5. Time Domain Reflectometry Versus. 


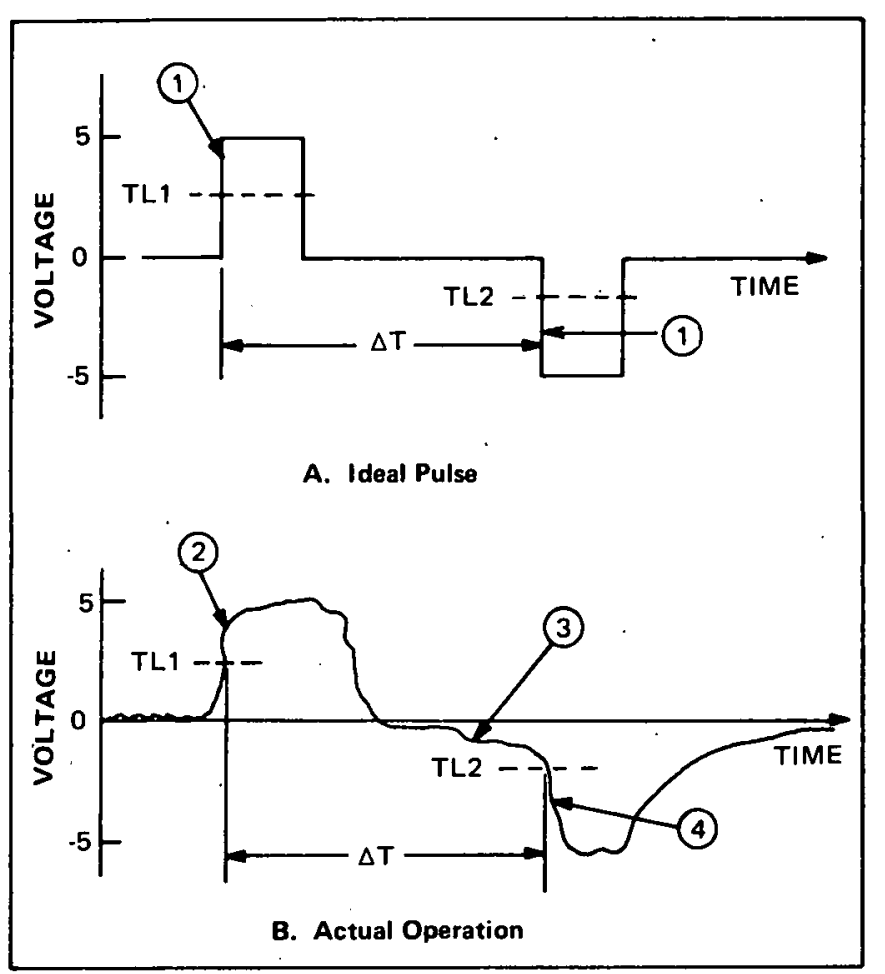

TL1 Trigger Level Voltage for Imitial Pulse.

TL2 Trigger Level Voltage for Reflected Pulse.

$\Delta T$ Time Interval Corresponding to the Level Measurement.

\# See Text.

FIGURE 6. Voltage Wave Forms.

The amount of electrolyte in the tank liquid unfortunately changes the shape of the reflected pulse. This effect is shown below:

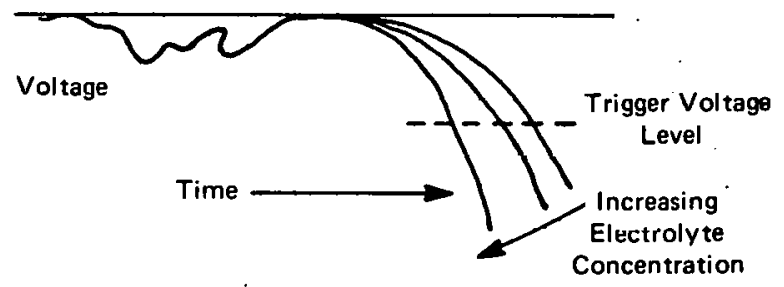

The time spread between liquids of different electrolyte concentration is least at low trigger voltages; however, the trigger voltage must be kept large enough to be above the noise and extraneous voltage reflection levels. The optimum reflected pulse trigger voltage was found to be -0.65 volts for this system and this voltage was used to obtain the data for Figure 5. By using special techniques it may be possible to reduce the difference in time readings for different

- electrolyte concentrations. Under present conditions it appears the best plan is to calibrate

- the system with a liquid very similar to the solution the tank will contain.
Experimental observation showed that the impedance discontinuity at the connection between the RG $58 \mathrm{c} / \mathrm{u}$ coaxial cable transmission line and liquid level probe does not cuase an objectional reflection, as shown in Figure 6B at Number 3.

\section{CONCLUSIONS}

Properly calibrated TDR instrumentation can be used to measure liquid levels in remote tanks within 3 millimeters (standard deviation) independent of liquid depth. The TDR level 'indication at the millimeter resolution level is affected by the electrolyte concentration in the liquid. To achieve maximum accuracy in process tankage, further development of probes and electronic instrumentation is needed. The present apparatus gives excellent results under laboratory conditions. The experimental equipment could easily be developed into process equipment able to make accurate, routine measurements of process tankage liquid levels.

A study should be made comparing the accuracy, reliability, and cost of other liquid level measurement systems with TDR. The TDR method is quite expensive for a single tank but the electronic equipment can serve many tanks, making the cost per tank reasonable for production tankage. ${ }^{6}$

\section{REFERENCES}

1. B. E. Dozer, "Liquid Level Measurement for Hostile Environment," Instrumentution Technology, February, 1967, p 55.

2. J. A. Strickland, Time-Domain Reflectometry Measurements, Beaverton, Oregon: Tektronix, Inc., 1970.

3. "Time Domain Reflectometry," HewlettPackard Journal, Vol. 15, No. 6, February, 1964, p 1.

4. L. W. Doher, "Volume Calibration of Process Vessels Using Digital Computer Techniques," USAEC RFP-488, 1966.

5. L. W. Doher, "Computerized Preparation of Calibration Scales: An Expansion of Process Vessel Volume Calibration Techniques," USAEC RFP-1413, June 1969.

6. L. W. Doher, Rocky Flats Division, Dow Chemical U.S.A., Personal communication, 1972. 